\title{
IS M-LEARNING A NEW WAY TO ATTRACT STUDENTS TO LEARN?
}

\author{
PAUla BAJDOR, ${ }^{1}$ DAMIAN DZIEMBEK ${ }^{2}$ \\ Częstochowa University of Technology, POLAND \\ ${ }^{1}$ e-mail: paula.bajdor@gmail.com \\ 2 e-mail: dziembek@poczta.zim.pcz.pl
}

RECEIVED
ACCEPTED
JEL
CLASSIFICATION

KEYWORDS

ABSTRACT
11 July 2017

15 December 2017

$120,123,125,033$

m-learning, education, mobile technology, mobile applications

M-learning is perceived as a new way of learning, which assume to use personal electronic devices, such as mobile phones, smart phones, tablets or palmtops. The only requirement is a unlimited access to the Internet. This could also be a new way to attract students - by offering them a new solution for studying. To check whether this concept would be accepted by students, the research has been conducted among the students, who are the e-learning platform's users. Based on the conducted research, Czestochowa University of Technology, may decide if this solution should be adopted as a new way of learning. The obtained results present that students are the users of electronic devices, such as smart phones, tablets or e-book readers, but still they are not fully convinced to m-learning.

\section{Introduction}

In polish reality the m-learning concept seems to be the new one. But in the literature, this issue was the subject of discussions at the beginning of the twenty-first century. The impetus for the creation of $m$-learning was the technological development leading to the invention of smart phones, tablets, notebooks and all kinds of mobile devices, that provide an access to the Internet, and are being owned by the masses of users. And caused the 
development of mobile social-networking applications (MSNAs) which enable communication between users (Wang, Chou, 2016). So it can be assumed that the use of these devices' capabilities for educational purposes was a matter of time. M-learning very often is defined as a form of e-learning, whose high popularity has arisen from the evolution of technology, and changed the way of materials' supply for the students (Sobolewska, 2015). Mobile learning involves the use of mobile technology, which is constantly evolving, in order to enable learning anytime and anywhere (Crescente, Lee, 2011). With mobile learning people can use mobile devices to access educational resources, connect with other users or even create content for learning. Mobile learning is also perceived as a branch of ICT in education (United Nations, 2013). It implies adapting and building upon the latest solutions in ICT technology, redefining the responsibilities of teachers and students, and blurring the lines between formal and informal learning (McQuiggan, Kosturko, McQuiggan, Sabourin, 2015).

M-learning is characterized by many features typical for e-learning, but unlike it, is being characterized by a greater flexibility of use, eg. e-learning causes the necessity of being in one place, while the m-learning removes this limitation (Hwang, Chang, 2011). Thus, m-learning is an extension and e-learning completion (Zhou, 2013). In addition, m-learning provides access to scientific contents, materials, dictionaries and tests or conducts personalized curriculum according to learning needs (Chen, Gillenson, Sherrell, 2002).

$\mathrm{M}$-learning in education is manifested by the fact, that teachers can prepare and lectures via notebooks or laptops. In turn, students having an unlimited access to the Internet, can check some issues, search for information and acquire knowledge (West, 2013). As I. Jacobs (2013) noted: "always on, always connected mobile devices in the hands of students has the potential to dramatically improve educational outcomes". They can also stay in constant contact with the teacher.

\section{Literature review}

By definition, m-learning refers not only to the education sector as a solution for the knowledge's acquisition, because the m-learning is also used by business which, for example provide trainings for their employees (Shuler, Winters, West, 2013). One of the first m-learning definition states that is "any sort of learning that happens when the learner is not at a fixed, predetermined location, or learning that happens when the learner takes advantage of the learning opportunities offered by mobile technologies" (MOBllearn, 2003). Quinn (2000) defined it as "the intersection of mobile computing and e-learning: accessible resources wherever you are, strong search capabilities, rich interaction, powerful support for effective learning, and performance-based assessment". According to definition given by Kukulska-Hume (2006) and Traxler (2007), m-learning is "all educational benefits, in which the mobile devices are the one or dominant used technology". Others, in turn, underline that mobile learning should not be limited to learn on devices, fitting to female purse or male pocket only (Keegan, 2016). M-learning, in particular, uses mobile devices, integrated with the respective applications to provide the content to the audience (Brown, 2005).

M-learning as an educational activity makes sense when used technology is fully mobile and when its users stay mobile while they learn. This emphasizes the mobility of learning and the significance of the "mobile learning" term (El-Hussein, Cronje, 2010).

It can therefore be assumed that if the m-learning is now quite popular form of learning, but this concept is still characterized by a growing trend, as its capabilities have not been fully utilized yet. 


\section{Method}

Unless the world, m-learning is widely used both in business and education, in Poland is still called a "niche trend", rarely used in the education sector. Having in mind the above, the main purpose of conducted research was to check how polish students perceive the m-learning concept. To carry out the research, students of the Faculty of Management of Czestochowa University of Technology were selected. More than 500 research questionnaires have been distributed among the students during the summer semester in 2016. For the final study only 446 questionnaires have been classified, some of them have not been returned and some did not meet the formal requirements.

The minimum sample size for estimating the probability of $p$ success in a general population, was calculated on the basis of the formula for sample size with a very large population:

$$
N_{\text {min }}=\frac{N_{p}\left(\alpha^{2} \times f(1-f)\right.}{N_{p} \times e^{2}+\alpha^{2} \times f(1-f)}=381,
$$

where:

$N_{\text {min }}$ - the minimum sample size,

$N_{p}$ - the size of the population,

$a^{2}$ - the confidence level for results,

$e^{2}-$ accepted level of highest error,

$f \quad$ - the size of the fraction.

This formula allows to obtain a predetermined accuracy of the estimation of population structure ratio. As is evident from the calculations, the minimum sample size, with the adopted confidence level $1-2=0.90$, and the accepted level of highest error $e=5 \%$, should be 381 questionnaires. Due to the fact that the study involved 446 questionnaires, it can be assumed that this condition has been met.

\section{Results}

As was mentioned earlier, the research questionnaire consists of three parts: the specifications, questions relating to the structure of income and expenditure and questions related to feelings of students with respect to its financial resources. The study involved 446 students, of which 264 were women (59\%) and $182-$ men (41\%). The vast majority of surveyed students were people between 19-20 years old. Students between 21-22 years old were found on the second place, and between 23-24 years old on the third place. In the case of students older than 24 years, only $6 \%$ of them were respondents of this research. However it is worth to note that conducted research have not been directed to the specific age group of students. Almost every respondent owns a laptop and smart phone. More than half have tablets, but only, $9 \%$ of them have an e-book reader. Laptop is a very popular device, in these days, it is cheap and necessary device, not only for study but for social life as well. Only a few students have admitted that they did not have laptop for their own purpose, but they use parents' laptops for work and leisure. The same situation can be observed in the case of smart phones - it is very rare to meet student using a traditional phone. This is caused that smart phones are quite cheap and offered by main mobile operators for a quite small amount. Five years ago tablets were owned by a small number of people - due to their price. But now, more than half of respondents own tablet, treating this device as an additional tool used for Internet, file sharing and games. 


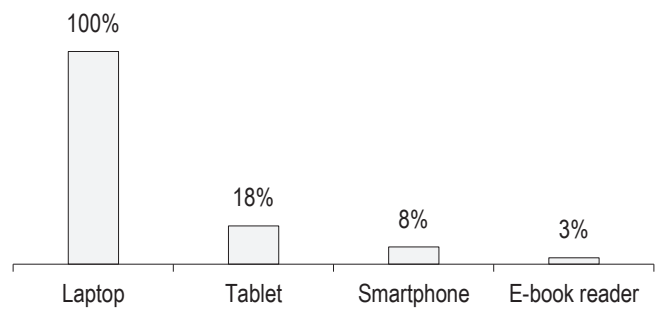

Figure 1. Devices used to learn

Source: own calculations' based on conducted research.

It is clearly visible from the above, that every respondent use a laptop to learn. And this is also a main device, because less than $20 \%$ use tablet, less than $10 \%$ use smart phone and less than $5 \%$ use e-book reader. Laptop is the most often used device, due to the fact that, as was mentioned earlier, almost every respondent owns this kind of device, and also it offers the most widest possibilities of use. Can be used in order to surf over the Internet, to meet and stay in touch with the others, it allows for music listening or documents writing. And, above all, the features, such as text, calculation or presentation editors, allow for the preparation for the classes. Tablets, due to their small screens are good for looking up for some information, smart phones are used to share the files and e-book readers are used to read the necessary materials, which are in the electronic form. But all the respondents have admitted that laptop is the first and main tool used to gain a new knowledge, do homeworks or prepare for exam.

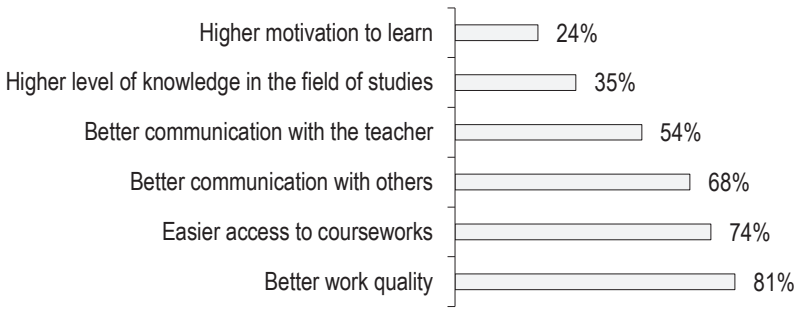

Figure 2. The advantages of m-learning

Source: own calculations' based on conducted research.

After the presentation the issue of m-learning, with its essence and main features description, with highlighting its presence in respondents studying mode, we have asked about the perceived pros and cons of m-learning. And as can be noticed on the figure above, to the main pros, the respondents included: better work quality, access to the courses and better communication with others. On the next places the following were found: better communication with the teacher, higher level of knowledge and higher motivation to learn. Under the better work quality, respondents understood faster knowledge acquisition, better preparation for classes and shorter time needed to learn. Because in opposite to traditional way of learning, in which students had to, in order to find new information, visit the library in person, now they simply run the Internet to find the necessary sources. And this leads to significant time savings. 
Access to the courses - here the respondents highlight the possibility of unlimited and constant access to materials, tutorials and courses. Also the need to attend the lectures have disappeared, as everyone can download this from the website. M-learning, in respondents' opinion, improves the communication between students and teachers as well. Thanks to it, students and teacher are able to set up a "special place" in Internet sphere, where they can communicate in order to share the information or find the answers. Higher motivation to learn was explained by m-learning attractiveness - this is quite new way of learning so attracts students, the various form of it caused that students are curious and willing to learn. This is also confirms the topic of this article - which can be treated as a hypothesis as well.

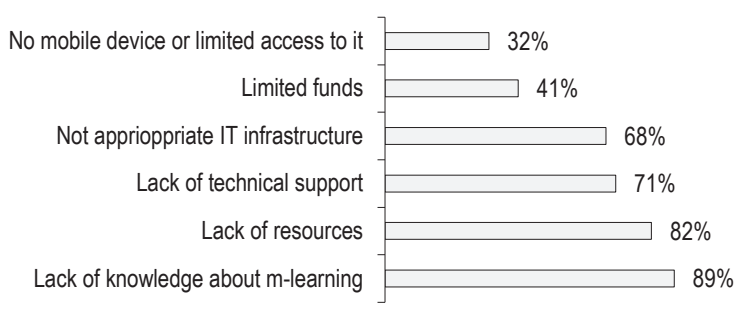

Figure 3. The disadvantages of m-learning

Source: own calculations' based on conducted research.

To the biggest disadvantages of $\mathrm{m}$-learning the respondents included: lack of knowledge about this concept, lack of resources, lack of technical support, not appropriate IT infrastructure, funds limitations and lack of mobile devices. From the obtained results we can assume that m-learning is quite new conception of learning, unknown to almost every respondent. From the name of it, respondents concluded that mainly it relies on using mobile devices in order to get educational information or gain a new knowledge, and these tools are equipped with appropriate applications. And basically they do not know more than this. That is why respondents have highlighted the lack of resources, technical support and weak IT infrastructure. On the one hand, these defects do not constitute defects in the concept of m-learning, but rather represent a lack of preparation, eg. from the university to implement this concept into practice, just by lack of resources, support and poor infrastructure. $32 \%$ respondents have highlighted another disadvantages such as no appropriate mobile devices or difficulties in accessing them, but it is more connected with the lack of knowledge on m-learning. Because respondents think that they need a special devices or application, especially dedicated to m-learning. While in real, a simple laptop, tablet or smart phone can be used instead.

Almost half of respondents have indicated the supplementary role of m-learning in education process. M-learning can also has an influence on attracting students in the learning process. $10 \%$ of respondents have indicated that $\mathrm{m}$-learning is a non-significant additional, with no influence on learning process. And only $4 \%$ think that $\mathrm{m}$-learning in the future, can fully replace the traditional learning. This distribution of answers can be dictated by the fact that $m$-learning is still a new way of learning for polish students, that is why they treat it as a supplement. We can speculate that in the future, when m-learning will become a common use way to learn, and thus will not be perceived as a supplement any more. 


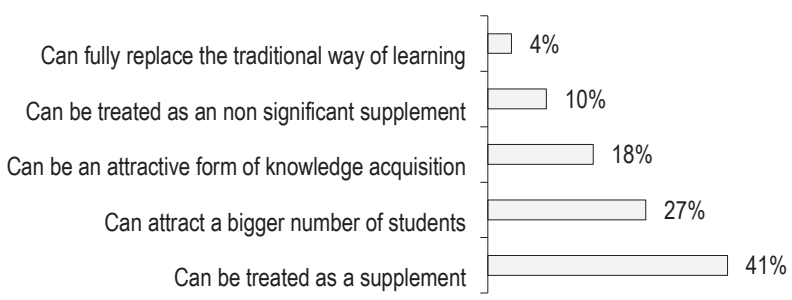

Figure 4. The role of m-learning in education

Source: own calculations' based on conducted research.

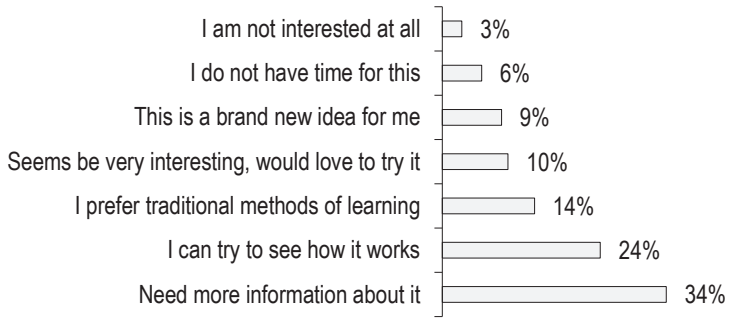

Figure 5. The overall insights on m-learning

Source: own calculations' based on conducted research.

And the last question was about the overall respondents' insights on m-learning. As we can see, almost $35 \%$ of them have indicated that they would need more information about m-learning. And then they would decide if it is worth to try or not. More than $20 \%$ are ready to try and see how m-learning works. $14 \%$ have highlighted that they preferred a traditional way of learning, but under "traditional" they understand using Internet, laptops and e-mails in order to gain or share information. So from this, we can conclude that "traditional" way of learning in the form of: reading paper books, visiting libraries or attending the lectures are no more traditional, but more old-fashioned. For $10 \%$ m-learning seems to be very interesting and they would love to try it in practice. $9 \%$ admitted that m-learning is really something new. The smallest part of respondents have highlighted that they did not have time for this and $3 \%$ have declared that they are not interested at all.

\section{Conclusions}

Today's reality is characterized by high dynamics of change and the widespread use of mobile devices, led not only to increase the information resources but also altered the way they transmit. Information must be short, contains the essence and adopts an attractive form. As a result, they are more quickly absorbed than information in the form of eg. long texts. At the moment, m-learning seems to be a new phenomenon, taken as a supplement or form attractive learning process. However, over a time it can become a commonly used mode of teaching. 
Polish student are active users of electronic devices, such as laptops, smartphones, tablets or e-book readers, but still they are not convinced if m-learning would be a useful learning tools. At present they can highlight some pros and cons, and they indicate readiness to try m-learning in their studies but they perceive it as a supplement only. According to the listed m-learning advantages, students have highlighted easier access to learning materials and easier communication with teacher or other students. That is why it is worth to repeat this research in the near future (1-2 years) to check if or how m-learning evolve and how students' attitude to m-learning has changed. But at first, to popularize m-learning among students, limitations such as: lack of resources, lack knowledge and lack of technical support should be removed. That is why, is possible to add one expectation to the expectations according to the m-learning's future development, which have been listed in the theoretical part of this article - the pressure should be put on better dissemination of knowledge about m-learning among the users, in that case - students and teachers. Not to mention that all efforts should be made in order to provide more and better resources and appropriate technical support.

\section{Referenences}

Brown, H.T. (2005). Towards a model for m-learning. International Journal on E-Learning, 3 (4), 299-315.

Chen, L-D., Gillenson, M.L., Sherrell, D.L. (2002). Enticing online consumers: an extended technology acceptance perspective. Information and Management, 8 (39), 705-719.

Crescente, M.L., Lee, D. (2011). Critical issues of M-Learning: design models, adoption processes, and future trends. Journal of the Chinese Institute of Industrial Engineers, 2 (28), 111-123.

El-Hussein, M.O.M., Cronje, J.C. (2010). Defining Mobile Learning in the Higher Education Landscape, Educational Technology \& Society, $3(13), 12-21$.

Hwang, G-J., Chang, H-F. (2011). A formative assessment-based mobile learning approach to improving the learning attitudes and achievements of students. Computers and Education, 4 (56), 1023-1031.

Irwin, J. (2013). Modernizing Education and Preparing Tomorrow's Workforce through Mobile Technology. Paper presented at the i4th Summit, March.

Keegan, D. (2016). The future of learning: From eLearning to mLearning. Retrieved from: http://learning.ericsson.net/mlearning2/ project_one/resources/articles.html (4.06. 2017).

Kukulska-Hulme, A., Pettit, J. (2006). Practitioners as innovators: emergent practice in personal mobile teaching, learning, work and leisure. Retrieved from: https://www.researchgate.net/publication/42798354_Practitioners_as_Innovators_Emergent_ Practice_in_Personal_Mobile_Teaching_Learning_Work_and_Leisure (4.06.2017).

McQuiggan, S., Kosturko, L., McQuiggan, J., Sabourin J. (2015). Mobile Learning. A Handbook for Developers, Educators, and Learners, SAS Institute. Retrieved from: https://www.sas.com/storefront/aux/en/spmled/67156_excerpt.pdf (2.11.2017).

MOBllearn (2003). Guidelines for learning/teaching/tutoring in a mobile environment. Retrieved from: https://www.researchgate.net/ publication/246347988_MOBllearn_D41_guidelines_for_learningteachingtutoring_in_a_mobile_environment (2.11. 2017).

United Nations (2013). Policy guidelines for mobile learning. Retrieved from: http://unesdoc.unesco.org/images/0021/002196/219641E. pdf (2.11. 2017).

Quinn, C. (2000). mLearning. Mobile, Wireless, In-Your-Pocket Learning. Retrieved from: http://www.linezine.com/2.1/features/ cqmmwiyp.htm (2.11.2017).

Sobolewska, O. (2015). E-learning społecznościowy - kierunki rozwoju nauczania zdalnego. In: W. Chmielarz, J. Kisielnicki \& T. Parys (eds.), Informatyka w społeczeństwie informacyjnym. Warszawa: Uniwersytet Warszawski.

Shuler, C., Winters, N., West, M. (2013). The future of mobile learning. Implications for policy makers and planners. Retrieved from: http://unesdoc.unesco.org/images/0021/002196/219637E.pdf (23.05.2017).

Traxler, J. (2007). Defining, Discussing and Evaluating Mobile Learning: The Moving Finger Writes and Having Writ... The International Review in Open and Distance Learning, 8, 1-13. 
Wang, E.S-T., Chou, N.P-Y. (2016). Examining social influence factors affecting consumer continuous usage intention for mobile social networking applications. International Journal of Mobile Communications, 1 (14), 43-55.

West, D.M. (2013). Mobile Learning: Transforming Education, Engaging Students, and Improving Outcomes, Center for Technology Innovation at Brookings.

Zhou, T. (2013). Understanding continuance usage of mobile services. International Journal of Mobile Communications, 1 (11), 56-70.

Cite this article aS: Bajdor, P., Dziembek, D. (2018). Is M-learning a new way to attract students to learn? European Journal of Service Management, 2 (26), 7-14. DOI: 10.18276/ejsm.2018.26-01. 